\title{
The relationship between environmental abundant electromagnetic fields and packaging shape to their effects on the 170 NMR and Raman spectra of $\mathrm{H} 2 \mathrm{O}-\mathrm{NaCl}$
}

\begin{abstract}
In this study, two identical groups of four containers with different packaging shapes made of polymethyl methacrylate (PMMA) were used to store $\mathrm{H} 2 \mathrm{O}-\mathrm{NaCl}$ solution for seven days at ambient room temperature $\left(25^{\circ} \mathrm{C}\right)$. Faraday shield was used to shield one group. The surrounding electromagnetic fields were measured during the storage period by using $\mathrm{R} \& \mathrm{~S} \circledast \mathrm{TS}-\mathrm{EMF}$ EMF measurement system. Samples of $\mathrm{H} 2 \mathrm{O}-\mathrm{NaCl}$ were collected at the end of the storage period and examined by 17 Oxygene nuclear magnetic resonance spectroscopy ( 17 O NMR) and Raman spectroscopy. Electromagnetic simulation was used to explore the relationship between the packaging shape of $\mathrm{H} 2 \mathrm{O}-\mathrm{NaCl}$ containers and the environmentally abundant electromagnetic fields to their effects on the cluster size of water. The study showed variations in the cluster size of water stored inside the two groups of containers. It was observed that the cluster size of water stored in the unshielded containers was lower than that of the shielded containers. The cluster size of water stored in the unshielded pyramidal container was lower than the cluster size of water stored in the unshielded rectangular, square, and cylindrical containers. The EM simulation results showed significant variations in the total specific absorption rate SAR and maximum point SAR values induced in the $\mathrm{H} 2 \mathrm{O}-\mathrm{NaCl}$ solution in the unshielded container models at $2400 \mathrm{MHz}$ for both vertical and horizontal polarization. It can be concluded that the variations in the values of SAR induced in $\mathrm{H} 2 \mathrm{O}-\mathrm{NaCl}$ solution are directly related to the variations in the cluster size of the stored water.
\end{abstract}

Keyword: Cluster size; Water; Packaging shape; EM simulation; NMR; Raman spectroscopy 